Check for updates

Cite this: RSC Adv., 2019, 9, 16375

\title{
Evaluation of dual layered photoanode for enhancement of visible-light-driven applications $\uparrow$
}

\author{
Suhee Kang, (D) a Joonyoung Jang, ${ }^{a}$ Hyo-Joon Kim, ${ }^{a}$ Sung-Hoon Ahn (D) ${ }^{b}$ \\ and Caroline Sunyong Lee (iD *a
}

Ternary structures consisting of hollow g- $\mathrm{C}_{3} \mathrm{~N}_{4}$ nanofibers/MoS $/$ sulfur, nitrogen-doped graphene and bulk g- $\mathrm{C}_{3} \mathrm{~N}_{4}$ (TCN) were designed as a dual layered film and fabricated using a spin-coating method. The first ternary structures were spin-coated on fluorine-doped tin oxide (FTO) glass, followed by spin-coating of $\mathrm{g}-\mathrm{C}_{3} \mathrm{~N}_{4}$ film to form dual layers. We characterized the microstructural morphologies, chemical composition/bonding and optical properties of the dual layered film and observed significantly reduced recombination rates of photo-induced electron-hole pairs due to effective separation of the charge carriers. We tested methylene blue (MB) photodegradation and observed remarkable MB degradation by the dual layered film over 5 hours, with a kinetic rate constant of $1.24 \times 10^{-3} \mathrm{~min}^{-1}$, which is about four times faster than that of bare TCN film. Furthermore, we estimated the $\mathrm{H}_{2}$ evolution of the dual layered film to be $44.9 \mu \mathrm{mol}$ over 5 hours, and carried out stable recycling over 45 hours under visible irradiation. Due to the lower electrochemical impedance spectroscopy (EIS) resistance value of the dual layered film ( $50 \mathrm{ohm} \mathrm{cm}^{2}$ ) compared to the TCN film, the ternary structures and bulk $\mathrm{g}-\mathrm{C}_{3} \mathrm{~N}_{4}$ film were well-connected as a heterojunction, reducing the resistance at the interface between the film and the electrolyte. These results indicate that the effective separation of the photo-induced electron-hole pairs using the dual layered film dramatically improved its photo-response ability under visible light irradiation.

Received 18th March 2019
Accepted 12th May 2019

DOI: 10.1039/c9ra02074h

rsc.li/rsc-advances represents less than $5 \%$ of the solar spectrum. ${ }^{12,13}$ Thus, band gap engineering is necessary to enhance the efficiency of photocatalytic activity within the specific range of the solar spectrum.

To utilize the visible band spectrum, other photoactive materials or hetero-combinations could be considered for labscale studies and future commercialization. In our previous study, one-dimensional hollow graphitic carbon nitride ( $\mathrm{g}$ $\left.\mathrm{C}_{3} \mathrm{~N}_{4}\right)$, molybdenum disulfide $\left(\mathrm{MoS}_{2}\right)$ and sulfur/nitrogen codoped graphene (SNG) were synthesized to respond only in the visible range via a one-pot hydrothermal method at a relatively low temperature. $\mathrm{g}-\mathrm{C}_{3} \mathrm{~N}_{4}$ is a metal-free polymeric semiconductor consisting of earth-abundant elements of carbon/ nitrogen, and is thus environmentally benign. ${ }^{14}$ The layered structures of $\mathrm{MoS}_{2}$-exposed sulfur atoms on Mo edges exhibit good stability, even in strong acids, as well as outstanding physical, optical and electrical properties. ${ }^{15,16}$ Sheet-like structures of graphene are well-known to possess two-dimensional $\mathrm{sp}^{2}$-hybridized carbon structures with high surface areas, high electrical conductivity, and good chemical stability, ${ }^{17-19}$ especially in the presence of defects due to sulfur or nitrogen doping. ${ }^{20,21} \mathrm{MoS}_{2}$ and $\mathrm{g}-\mathrm{C}_{3} \mathrm{~N}_{4}$ are used to reduce electrons and oxidize holes, respectively, because their electronic properties well match their conduction and valence bands,..22 Moreover, SNG has also been used to enlarge active sites, thus accelerating charge transport. ${ }^{23}$ Despite these suitable materials, bulk type
${ }^{a}$ Department of Materials and Chemical Engineering, Hanyang University, South Korea. E-mail: sunyonglee@hanyang.ac.kr

${ }^{b}$ Department of Mechanical and Aerospace Engineering, Seoul National University, South Korea

$\dagger$ Electronic supplementary information (ESI) available. See DOI: $10.1039 / \mathrm{c} 9 \mathrm{ra} 02074 \mathrm{~h}$ 
catalyst powders still have serious problems because they agglomerate in aqueous solution, resulting in rapid recombination rates of photo-induced charge carriers. ${ }^{\mathbf{2 4 2 5}}$ Moreover, a particulate form of photocatalysts tend to decrease the photocatalytic efficiency due to light scattering or charge recombination. $^{26}$ To overcome this, as-synthesized powders were prepared as a photoanode film using a simple spin-coating method, thus improving their photocatalytic activity.

In this study, we spin-coated a dual layered photoanode film using a ternary structure of hollow g- $\mathrm{C}_{3} \mathrm{~N}_{4}$ nanofibers (HGCNF)/ $\mathrm{SNG} / \mathrm{MoS}_{2}$ followed by bulk $\mathrm{g}-\mathrm{C}_{3} \mathrm{~N}_{4}$ from thiourea precursors (denoted as TCN) for photo-responsive applications. The ternary structures were first spin-coated onto FTO substrates and the bulk $\mathrm{g}-\mathrm{C}_{3} \mathrm{~N}_{4}$ was then spin-coated onto ternary structures. Finally, we obtained the dual layered film and demonstrated its increased absorption under the visible spectrum; we also reduced its band gap energy compared to that of bare TCN film. To confirm the photo-responsivity of the film, we carried out photocatalytic activities, organic pollutant degradation on methylene blue (MB) and $\mathrm{H}_{2}$ evolution, using the as-prepared photoanode films, namely the TCN and dual layered film, under visible light irradiation. The dual layered film achieved faster pollutant removal, as well as higher $\mathrm{H}_{2}$ production, due to its heterojunctions of ternary structures and TCN, and is thus suitable for various photo-responsive applications.

\section{Experimental section}

\subsection{Materials}

To supply sulfide from molybdenum sulfide, SNG, and bulk g$\mathrm{C}_{3} \mathrm{~N}_{4}$, thiourea was purchased from Wako (Japan). Sodium molybdate $\left(\mathrm{NaMoO}_{4}\right)$ was purchased from Sigma-Aldrich (Germany). Sodium sulfate $\left(\mathrm{Na}_{2} \mathrm{SO}_{4}\right)$ and triethanolamine (TEOA) were purchased from SAM-CHUN (Korea). $\mathrm{H}_{2} \mathrm{PtCl}_{2}$ was purchased from Sigma-Aldrich (USA) for $\mathrm{H}_{2}$ evolution reactions. A conductive fluorine-doped tin oxide (FTO, $15 \mathrm{~m} \Omega$ ) substrate was used as the photoanode film. Liquion solution was purchased from Ion Power (USA) to be mixed with powder for spin-coating. All chemicals were used directly without any further purification.

\subsection{Preparation of catalysts of ternary structures and bulk $\mathrm{g}$ - $\mathbf{C}_{3} \mathbf{N}_{4}$}

To prepare the ternary structure of $\mathrm{HGCNF} / \mathrm{SNG} / \mathrm{MoS}_{2}$, we followed the synthesis procedure used in our previous study. ${ }^{27}$ Briefly, $0.1 \mathrm{~g}$ of HGCNF were sonicated using an ultra-high sonicator for $30 \mathrm{~min}$ in GO solution/distilled water (4:96 v/v\%). Afterwards, the dispersion solution was stirred with $0.4 \mathrm{~g}$ of $\mathrm{Na}_{2} \mathrm{MoO}_{4}$ precursor for 1 hour. Then, $0.8 \mathrm{~g}$ of thiourea precursor was added to the solution until it had dissolved completely. After dissolving, a hydrothermal process was carried out under the same conditions. Due to the SNG, the obtained product was freeze-dried after filtration with distilled water and ethanol. Furthermore, the thiourea precursor was used for sintering in a covered crucible at a temperature of up to $520^{\circ} \mathrm{C}$ for 2 hours $\left(5^{\circ} \mathrm{C} \mathrm{min}{ }^{-1}\right)$ to produce bulk $\mathrm{g}_{-} \mathrm{C}_{3} \mathrm{~N}_{4}$. Finally, we fabricated as-prepared black-colored
HGCNF/SNG/MoS 2 , which we called ternary structures, while the as-prepared yellow-colored bulk g- $\mathrm{C}_{3} \mathrm{~N}_{4}$ was called TCN.

\subsection{Fabrication of photoanode films}

To fabricate the dual layered photoanode film using these catalysts, $0.2 \mathrm{~g}$ of ternary structure powder and TCN powder were prepared separately in $2 \mathrm{~mL}$ of Liquion solution until dissolved completely. Then, $0.5 \mathrm{~mL}$ of as-prepared ternary structure solution was spin-coated on FTO glass $(2 \mathrm{~cm} \times 5 \mathrm{~cm})$ at $2500 \mathrm{rpm}$ for $60 \mathrm{~s}$. and dried in an oven for 2 hours. After drying the film, $0.5 \mathrm{~mL}$ of TCN solution was dropped onto the as-fabricated ternary structure under the same spin-coating conditions and dried in the oven for 2 hours. Finally, the fabricated photoanode film was sintered at $150{ }^{\circ} \mathrm{C}$ for 1 hour under ambient atmosphere to remove the solvent, after which we stabilized the film. For the comparison, each ternary structure and TCN solution was separately spin-coated on the FTO substrate using the same procedure described above.

\subsection{Characterization}

We differentiated the well-constructed morphologies of the photoanode film using field-emission scanning electron microscopy (FE-SEM; model S4800, Hitachi, Japan), focused ion beam (FIB; model FB-2100, Hitachi, Japan) and transmission electron microscopy (TEM; model JEM-2100F, JEOL, Japan). To observe the crystalline structure and its properties, X-ray diffraction (XRD) using a $\mathrm{Cu} \mathrm{K} \alpha$ source (model D/Max-2500/PC; Rigaku/USA Inc., USA) analysis was carried out on the $\mathrm{MoS}_{2}$ and $\mathrm{g}-\mathrm{C}_{3} \mathrm{~N}_{4}$ phases. Fourier transform infrared spectroscopy (FTIR; model iS10; Thermo Fisher Scientific, UK) and X-ray photoelectron spectroscopy (XPS) using an $\mathrm{Al} \mathrm{K} \alpha$ source (Sigma Probe; Thermo Fisher Scientific, UK) were used to confirm the formation of $\mathrm{g}-\mathrm{C}_{3} \mathrm{~N}_{4}$. Then, UV-VIS spectroscopy (model V650; JASCO, Japan) was used to observe the optical absorbance of the films so that we could calculate their band gap energy. Photoluminescence (PL; SC-100; Dongwoo, Korea) was employed to monitor the recombination rate of the as-prepared films at $325 \mathrm{~nm}$ laser excitation. All photocatalytic performance tests of transient photocurrents, Mott-Schottky analysis and electrochemical impedance spectroscopy (EIS) were carried out using a potentiostat (VersaSTAT 4; Princeton Applied Research, USA). The photocatalytic degradation solutions were measured by UV-VIS spectroscopy.

\subsection{Photocatalytic performance}

Three different photocatalytic experiments were carried out using the photoanode films. The PEC measurements of the transient photocurrent and EIS proceeded under a threeelectrode quartz system with a VersaSTAT 4 potentiostat (Princeton Applied Research) in $0.5 \mathrm{M} \mathrm{Na}_{2} \mathrm{SO}_{4}$. The transient photocurrent was applied at $1 \mathrm{~V}$ of bias potential versus an $\mathrm{Ag} /$ $\mathrm{AgCl}$ reference electrode, while chopping the illumination to study the response of the sample to light. The flat band potential was measured at a potential range of -0.5 to $1 \mathrm{Vvs.} \mathrm{Ag/}$ $\mathrm{AgCl}$ with selected frequencies and an amplitude of $10 \mathrm{mV}$ in $0.5 \mathrm{M} \mathrm{Na}_{2} \mathrm{SO}_{4}$. The electrochemical impedance was measured at a frequency of $10^{5}$ to $0.1 \mathrm{~Hz}$ with an alternating current (AC) 
amplitude of $20 \mathrm{mV}$ (biased at $1 \mathrm{~V}$ ). We used MB pollutant to observe the organic pollutant removal properties of the samples. Before starting the experiment, $0.02 \mathrm{mM}$ of $\mathrm{MB}$ solution was prepared with distilled water. Then, $90 \mathrm{~mL}$ of $\mathrm{MB}$ solution was added to a $100 \mathrm{~mL}$ Pyrex glass beaker and the photoanode film was clipped with a tweezer to irradiate its surface. After initiating the irradiation, $3 \mathrm{~mL}$ of solution was collected every hour until the degradation was complete. For the active species, the scavenger test was carried out to study photocatalytic mechanism. Before starting the degradation, each scavenger of EDTA $(1 \mathrm{mM}), t$-BuOH $(1 \mathrm{mM})$ and saturated $\mathrm{N}_{2}$ was added into MB solution. After stirring the solution, the photocatalytic activity was proceeded under same condition. We used a $100 \mathrm{~mL}$ Pyrex glass beaker in the same way to investigate the $\mathrm{H}_{2}$ evolution of photoanode films. Then, $25 \mathrm{vol} \%$ of trimethylamine (TEOA) in $60 \mathrm{~mL}$ of aqueous solution was added as a hole scavenger. To enhance its properties, we photodeposited $1 \mathrm{wt} \%$ of platinum (Pt) on the photoanode film with UV irradiation for $5 \mathrm{~min}$. Prior to the reaction, the reactor was sealed with a septum and $\mathrm{N}_{2}$ gas was purged into an aqueous solution to remove oxygen $\left(\mathrm{O}_{2}\right)$ from the solution. After that, argon (Ar) gas was purged into the reactor to completely eliminate the air. The produced gas was detected using a pulsed discharge detector (PDD) equipped with gas chromatography (GC; model 6500GC; YL Instruments, Korea) and helium gas was employed as a carrier gas. To assess the photocatalytic performance, a $300 \mathrm{~W}$ Xe-arc lamp (model 66984; Newport, USA) was used with a UV cut-off filter $(>400 \mathrm{~nm})$. The stability test was repeated nine times under the same conditions.

\section{Results and discussions}

\subsection{Morphology and characterization of photoanode films}

Fig. 1(a)-(c) show SEM images of the surface morphology of the ternary structures, TCN and dual layered films. The ternary structures were well spin-coated on the FTO substrate with its fabricated composites (HGCNF, $\mathrm{MoS}_{2}$ and SNG), while TCN film was spin-coated onto FTO glass with only bulk g- $\mathrm{C}_{3} \mathrm{~N}_{4}$ structures. When the TCN was coated on the ternary structures, the TCN was entirely wrapped around the ternary structures and partial HGCNFs were observed, as shown in the top view. Fig. 1(d)-(f) show cross-sectional images of the FTO substrate, which we used to assess the coating thickness. The ternary structures and TCN had thicknesses of 3.99 and $2.34 \mu \mathrm{m}$, respectively. In the case of the dual layered film, the blue dotted line shows the separation between the TCN, ternary structures and FTO. TCN was coated onto the ternary structures along the dotted curve, indicating its total thickness to be $4.17 \mu \mathrm{m}$, while the ternary structures are shown between the dotted line of the ternary structures to the dotted curve of the TCN. Furthermore, the cross-sectional TEM image of dual layered film was observed to confirm that heterojunction between ternary structures and bulk g- $\mathrm{C}_{3} \mathrm{~N}_{4}$ was well-connected as shown in Fig. S1.† Fig. S1† indicated that the ternary structures with TCN on the FTO glass, formed a well-connected heterojunction. According to the microstructures of these films, the dual layered film demonstrated good formation of ternary structures with bulk g- $\mathrm{C}_{3} \mathrm{~N}_{4}$ structures (TCN).

The crystalline phases of the as-prepared samples were observed using XRD analysis, as shown in Fig. 2(a). The peaks for the crystalline $\mathrm{MoS}_{2}$ patterns appeared at 12.02, 33.34, 38.83 and $58.9^{\circ}$, which are indexed to the (002), (100), (103) and (110) planes (JCPDS no. 37-1492), ${ }^{28}$ respectively. In the case of the ternary films, the sharp diffraction peaks indicate high crystallinity of $\mathrm{MoS}_{2}$. We observed the $\mathrm{g}-\mathrm{C}_{3} \mathrm{~N}_{4}$ peak from the TCN and dual layered films at $27.3^{\circ}$, which corresponds to the (002) plane, indicating the inter-planar spacing of aromatic systems. ${ }^{29}$ Due to the photoanode film of the FTO substrate, the diffraction peaks of the $\mathrm{SnO}_{2}$ phase were detected by XRD analysis according to JCPDS no. 01-070-6995. ${ }^{30}$ We also used FT-

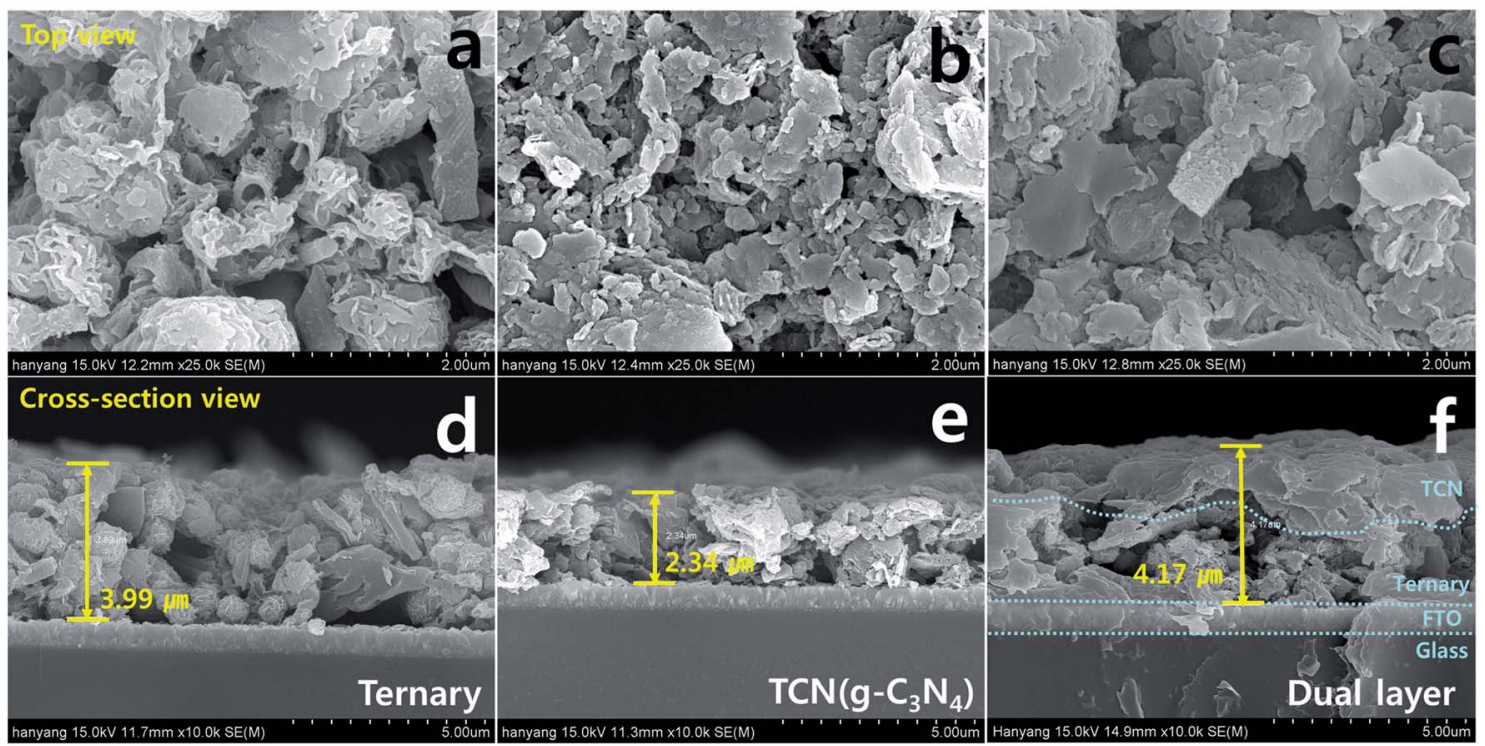

Fig. 1 Top view scanning electron microscopy (SEM) images of (a) ternary film, (b) TCN film, and (c) dual layered film, and cross-sectional images of (d) ternary film, (e) TCN film, (f) and dual layered film (blue dotted lines indicate interfaces between different layers). 

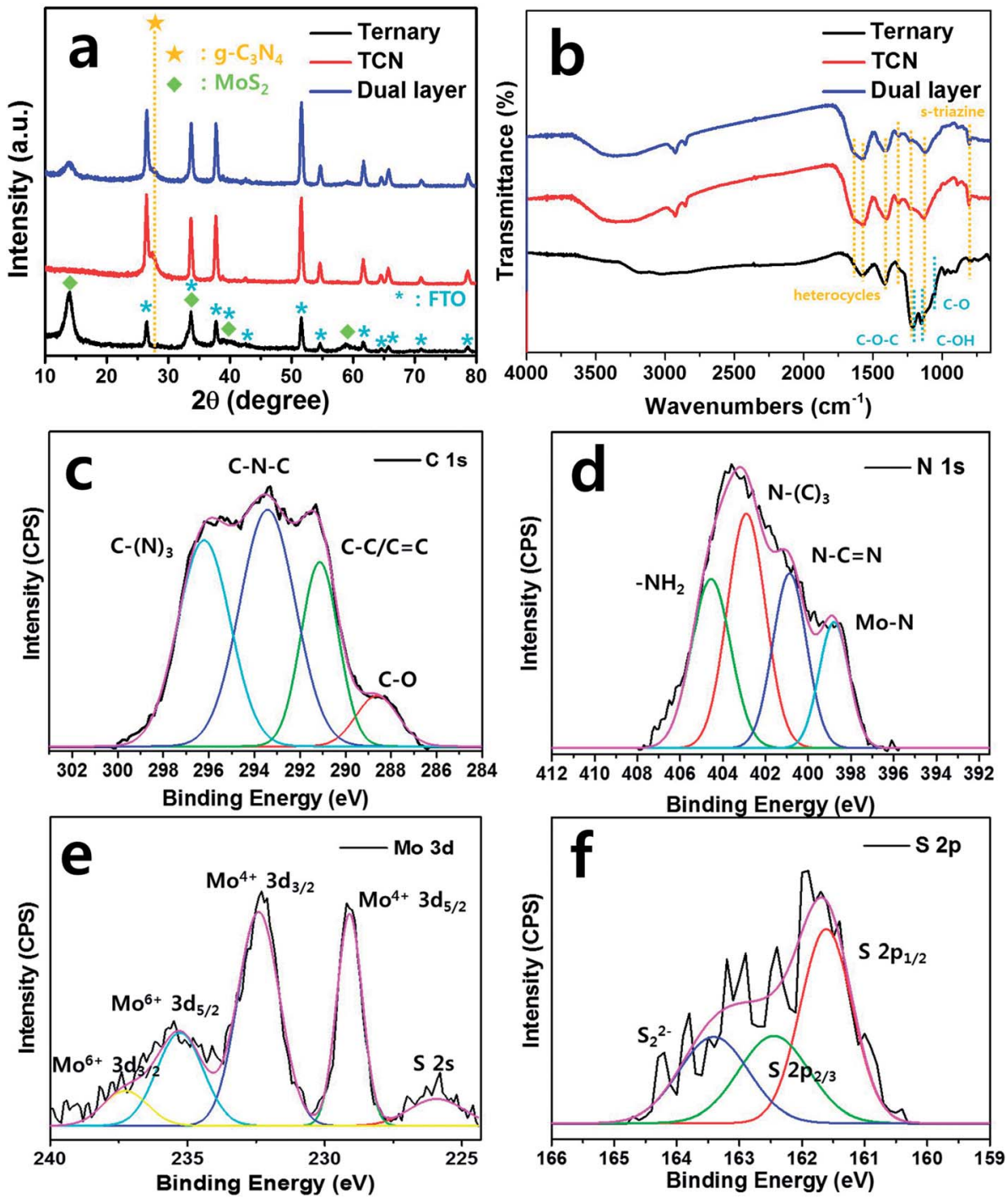

Fig. 2 Characterization analysis of ternary film, TCN film and dual layered film. (a) X-ray diffraction, and (b) Fourier transform infrared and X-ray photoelectron spectroscopy fitting data on dual layered film of (c) C 1s, (d) N 1s, (e) Mo 3d and (f) S 2p.

IR to analyze the chemical molecular composition of the $\mathrm{g}-\mathrm{C}_{3} \mathrm{~N}_{4}$ structures. The ternary, bare TCN and dual layered films exhibited C-N heterocycles at wavenumbers 1577.8, 1399.6, $1313.2,1131.8 \mathrm{~cm}^{-1}$, and s-triazine units at $806.8 \mathrm{~cm}^{-1}$. For the ternary film, it showed graphene-related FT-IR peaks of C-O-C, $\mathrm{C}-\mathrm{O}$ and $\mathrm{C}-\mathrm{OH}$ at $1212.2,1146.7$ and $1057.1 \mathrm{~cm}^{-1}$, respectively since the ternary structure is surrounded by sulfur/nitrogendoped graphene (SNG). ${ }^{31,32}$ As shown in Fig. 2(b), the $g-\mathrm{C}_{3} \mathrm{~N}_{4}$ specific groups were shifted when the TCN was coated on ternary structures. The heterocycle rings of dual layered film were detected at 1577.9, 1400.5, 1312.9, $1124.3 \mathrm{~cm}^{-1}$, which we attributed to the aromatic $\mathrm{C}=\mathrm{N}$ and $\mathrm{C}-\mathrm{N}$ stretching vibration. Furthermore, s-triazine units for graphite-like $\mathrm{sp}^{2}$ bonding state were presented at $804.9 \mathrm{~cm}^{-1}$ due to the breathing mode. ${ }^{33}$ The broad peaks at $3400-3000 \mathrm{~cm}^{-1}$ denoted amine $(\mathrm{N}-\mathrm{H})$ and hydroxyl $(\mathrm{O}-\mathrm{H})$ stretching modes. ${ }^{34}$ Based on the results of our XRD and FT-IR analysis, the dual layered film was well formed, coating ternary structures with TCN.
To confirm the characterization of the $\mathrm{g}-\mathrm{C}_{3} \mathrm{~N}_{4}$ and ternary structures of the dual layered film, we carried out XPS fitting analysis to investigate the chemical bonding based on the binding energy. In the $\mathrm{C}$ 1s spectrum (Fig. 2(c)), the main three Gaussian peaks were deconvoluted at 291.1, 293.4 and $296.2 \mathrm{eV}$, which we assigned to the graphitic carbon bonding of the $\mathrm{C}-\mathrm{C} /$ $\mathrm{C}=\mathrm{C}, \mathrm{N}$ atoms in the lattice of the $\mathrm{g}-\mathrm{C}_{3} \mathrm{~N}_{4}$ group with defect $\mathrm{sp}^{3}$ carbon atoms in $\mathrm{C}-\mathrm{N}-\mathrm{C}$, and to $\mathrm{sp}^{2}$-hybridized carbon in the triazine group of $\mathrm{C}-(\mathrm{N})_{3}$, respectively. ${ }^{35}$ The peak of the $\mathrm{C}-\mathrm{O}$ bond at $288.6 \mathrm{eV}$ was attributed to the $\mathrm{O}_{2}$ species around the $\mathrm{sp}^{2}$-hybridized carbon in the $\mathrm{g}-\mathrm{C}_{3} \mathrm{~N}_{4} \cdot{ }^{36}$ The main peaks in the $\mathrm{N}$ 1s spectrum were assigned to $\mathrm{sp}^{2}$-hybridized $\mathrm{N}_{2}$ of $\mathrm{C}-\mathrm{N}=\mathrm{C}$ $(400.9 \mathrm{eV})$, and tertiary $\mathrm{N}_{2}$ of $\mathrm{N}-(\mathrm{C})_{3}(404.6 \mathrm{eV})$ and $-\mathrm{NH}_{2}(402.9$ $\mathrm{eV}$ ), as shown in Fig. 2(d). ${ }^{37}$ In particular, we made novel observations of Mo-N bonding at $398.8 \mathrm{eV}$, which indicated the deep heterojunction between $\mathrm{g}-\mathrm{C}_{3} \mathrm{~N}_{4}$ and $\mathrm{MoS}_{2} \cdot{ }^{29}$ The obtained main peaks for $\mathrm{Mo}^{4+} 3 \mathrm{~d}_{5 / 2}$ and $\mathrm{Mo}^{4+} 3 \mathrm{~d}_{3 / 2}$ were centered at 229.1 and $232.4 \mathrm{eV}$, respectively, providing typical values of $\mathrm{Mo}^{4+}$ 
species, as shown in Fig. 2(e). The peaks were observed at $235.3 \mathrm{eV}$ for $\mathrm{Mo}^{6+} 3 \mathrm{~d}_{5 / 2}$ and $237.3 \mathrm{eV}$ for $\mathrm{Mo}^{6+} 3 \mathrm{~d}_{3 / 2}$, possibly due to slight oxidation of the $\mathrm{MoS}_{2}$ surface into molybdenum oxide $\left(\mathrm{MoO}_{3}\right){ }^{38,39}$ Theoretically, XRD identifies the crystalline phase of the materials within its thickness of $10 \mu \mathrm{m}$ from the surface while XPS identifies the oxidation state of the materials from the chemical binding energies even with ultra-thin layer. ${ }^{\mathbf{4 0 , 4 1}}$ Thus, slight oxidation of $\mathrm{MoO}_{3}$ from the surface of $\mathrm{MoS}_{2}$ was estimated based on the detection of $\mathrm{Mo}^{6+}$ peaks from XPS analysis although $\mathrm{MoO}_{3}$ was not detected in XRD analysis. ${ }^{42}$ The peak was located at $225.9 \mathrm{eV}$, which we attributed to $\mathrm{S} 2 \mathrm{~s}$. Fig. 2(f) indicates two strong peaks at 161.6 and $162.4 \mathrm{eV}$, corresponding to $S 2 p_{2 / 3}$ and $S 2 p_{1 / 3}$, respectively, in the $S 2 p$ spectrum of the dual layered film. Moreover, a broad peak was observed at $162.8 \mathrm{eV}$, indicating bridged $\mathrm{S}_{2}{ }^{2-}$ or apical $\mathrm{S}_{2}{ }^{-{ }^{-43,44}}$. Therefore, these observations confirmed the successful formation of dual layered film using ternary structures with TCN.

\subsection{Optical properties for band diagram}

We also assessed the optical properties of the samples to evaluate their absorbance properties with respect to their band gap energy. As shown in Fig. 3(a), the ternary film exhibited higher absorption than TCN or dual layered films in the UV-VIS region, without band edges. Due to the black color of the film, only the ternary film absorbed the entire light spectrum, while both the TCN and dual layered films exhibited a band edge in the visible region at a wavelength of approximately $450 \mathrm{~nm}$, suggesting higher activity than bare ternary film when exposed to light. Moreover, the dual layered film exhibited increased absorption in the visible region compared to that of TCN film. We calculated the band gap energies of the TCN and dual layered films, as shown in Fig. 3(b). The band gap energy of the TCN film showed the typical bulk g- $\mathrm{C}_{3} \mathrm{~N}_{4}$ band gap energy to be $2.56 \mathrm{eV} \cdot{ }^{14}$ If the ternary structures and TCN were formed as a dual layer, the band gap would obviously be shifted into lower energy, corresponding to our measured value of $1.64 \mathrm{eV}$. The photoluminescence (PL) was measured to obtain the recombination of charge carrier status for the as-prepared films under excitation laser of $325 \mathrm{~nm}$. As a result, there was no emission of PL intensity observed from the ternary structure as shown in Fig. S2. $\uparrow$ The TCN film exhibited the highest PL intensity, while the dual layered film exhibited the lowest PL intensity. Based on our PL results (Fig. 3(c)), it can be seen that the dual layer formed successful heterostructures between the ternary composite and the TCN, promoting reduction of the recombination of photo-excited electron-hole pairs. We analyzed the transient photocurrent to observe the responses of the samples to visible irradiation. The photocurrent was measured by lightchopping in on-off cycles. In Fig. 3(d), the TCN and dual layered film exhibited photocurrents of 0.5 and $12.6 \mu \mathrm{A}$, respectively. When the light was on, both films exhibited a steady-state photocurrent. ${ }^{45}$ However, when the light was off, interestingly, the photo-response of the dual layered film was much slower than that of the TCN. The slow photocurrent indicated superior charge carrier separation, increasing the carrier lifetime. Thus, the dual layered film reduces the recombination rate through the interface between the ternary structures and TCN, yielding a 25-fold improvement in the photo-response under visible illumination.

To determine the band structure of the as-prepared films, flat band potential was measured and plotted using MottSchottky. As shown in Fig. 3(e), the TCN and dual layered film indicated positive slopes in the plots, suggesting n-type semiconductors. The flat band potential of both TCN and dual layered film are shown to be independent of different frequencies from the same $x$-intercept. The flat band potentials of TCN and dual layer are estimated to be -1.15 and $-0.93 \mathrm{eV}$, respectively. For the case of n-type semiconductors, the flat band potentials are equal to that of CB (conduction band) and the estimated flat potential value can be acted as the potential for CB. According to the bandgap measurement with flat band potential, the VBs (valence bands) of TCN and dual layer were calculated to be 1.41 and $0.71 \mathrm{eV}$, respectively. Finally, the band diagram of TCN and dual layered film was shown in Fig. 3(f), confirming that dual layer can facilitate the electron and hole pairs during the photocatalytic performances compared to that of TCN film due to its suitable band position.

\subsection{Methylene blue photodegradation}

The MB photodegradation of the as-fabricated photoanode films was carried out under visible light illumination. Fig. S3(a) $\dagger$ shows the experimental set-up for photocatalytic degradation with a xenon-arc lamp using $>400 \mathrm{~nm}$ cut-off filter. Fig. 4(a) and (b) demonstrate the MB pollutant absorbance of TCN and dual layered films against wavelengths between 600$650 \mathrm{~nm}$. The photocatalytic degradation activity began at $0 \mathrm{~min}$ and continued up to full degradation at $300 \mathrm{~min}$. When the light was illuminated, the photoanode film started to remove the MB pollutant over time. Commonly, bulk graphitic carbon nitride has shown the adsorption properties or organic dyes even under the dark condition. Due to its porous structure of graphitic carbon nitride, the dye can be adsorbed easily on that of surface. ${ }^{46}$ To verify the adsorption ability of as-prepared films, the photocatalytic performance was carried out under dark condition for $30 \mathrm{~min}$. After that, the adsorption ability was clearly observed through optical absorbance analysis. As a result, TCN film has adsorbed $2.7 \%$ of the MB dye while the dual layered film showed much higher adsorption properties of $6.9 \%$ than that of TCN film due to dual layer of porous structure. Therefore, the TCN film has shown slight pollutant removal until $300 \mathrm{~min}$. When the TCN was coated onto the ternary film, resulting in a dual layer of heterostructured film, the MB degradation proceeded faster than when pure TCN film was used, removing the organic pollutant after up to $300 \mathrm{~min}$. We assessed the kinetic rate constant by calculating the MB concentration, which is plotted in Fig. 4(c). For comparison, pure MB degradation was monitored without a photoanode film under the same conditions and the blank solution shows the degradation results. Hence, MB degradation on photoanode films follows a pseudo-first-order equation, called the Langmuir-Hinshelwood $(\mathrm{L}-\mathrm{H})$ mechanism. ${ }^{47}$ The $\mathrm{L}-\mathrm{H}$ mechanism is defined as: 

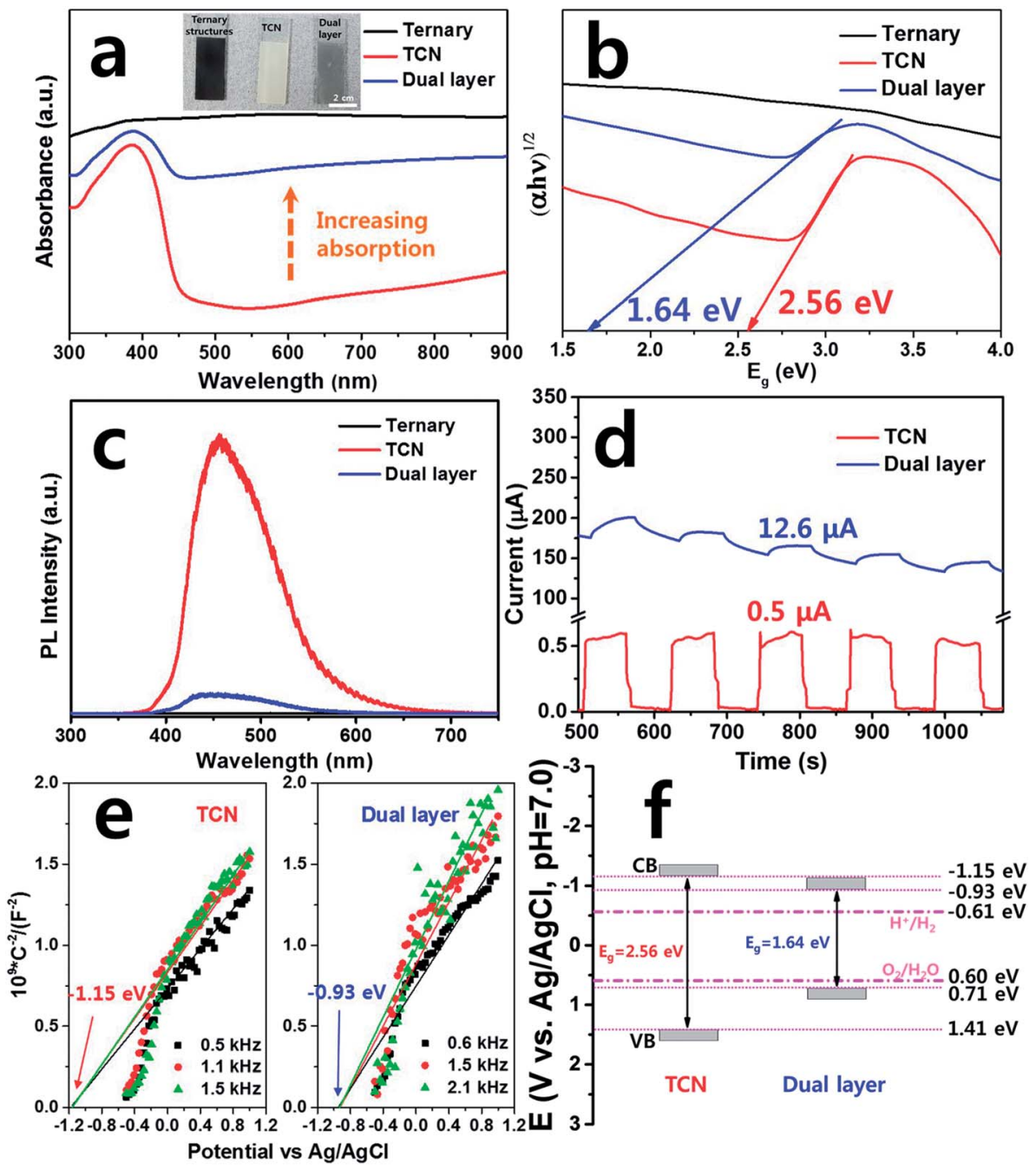

Fig. 3 Photoresponse analysis of (a) optical absorbance (inset; image of films), (b) calculated band gap energy, (c) photoluminescence of ternary film, TCN film and dual layered film, and (d) transient photocurrent, (e) flat band potential analysis using Mott-Schottky measurement and (f) band diagram of TCN film and dual layered film.

$$
-\ln \left(C / C_{0}\right)=k t
$$

Based on eqn (1), $-\ln \left(C / C_{0}\right)$ showed linear plots and $k$ is the kinetic rate constant $\left(\mathrm{min}^{-1}\right)$ of the catalytic degradation activity. ${ }^{48}$ The $k$ value of the dual layered film was calculated to be $1.24 \times 10^{-3} \mathrm{~min}^{-1}$, which was about four times higher than that of TCN film $\left(0.34 \times 10^{-3} \mathrm{~min}^{-1}\right)$, as shown in Fig. $4(\mathrm{~d})$. In the case of the MB itself, the $k$ value was calculated to be $0.07 \times$ $10^{-3} \min ^{-1}$.

To study the photocatalytic mechanism in detail, the scavenger test of dual layer was carried out using EDTA-2Na (EDTA), $t$-butanol $(t$-BuOH $)$ and nitrogen $\left(\mathrm{N}_{2}\right)$ as hole $\left(\mathrm{h}^{+}\right)$capture, hydroxyl radical $(\cdot \mathrm{OH})$ and superoxide radical $\left(\cdot \mathrm{O}_{2}{ }^{-}\right)$, respectively under the same condition of the photocatalytic performance as shown in Fig. $4(\mathrm{e})$ and (f). The $\mathrm{N}_{2}$ was added into $\mathrm{MB}$ solution with dual layer, showing the similar degradation efficiency of $53 \%$ compared to that of dual layered film (61\%). This demonstrated that superoxide radical was negligible in the photocatalytic reaction. However, when the $t-\mathrm{BuOH}$ and EDTA were added into methylene blue solution, the degradation rate of $t$-BuOH and EDTA decreased to lower the degradation efficiencies to be $19 \%$ and $30 \%$, respectively compared to those of other scavengers. As a result, we can clearly see that $\mathrm{h}^{+}$and $\cdot \mathrm{OH}$ were the main active species during the MB photocatalytic degradation activity.

The detailed photodegradation process is explained as follows: When visible light was irradiated onto the dual layered film, photoinduced electron and hole pairs were generated on the surface of the dual layered film. In the TCN conduction band, the electron $\left(\mathrm{e}^{-}\right)$transferred from the valence band reacted with the attached $\mathrm{O}_{2}$ molecules on the TCN surface to produce $\mathrm{O}_{2}$ radicals, $\cdot \mathrm{O}_{2}{ }^{-}$. The $\cdot \mathrm{O}_{2}^{-}$radicals eventually degraded the MB dye into the water. ${ }^{49}$ Meanwhile, the hole $\left(\mathrm{h}^{+}\right)$ from the TCN valence band reacted with the $\mathrm{OH}$ in the aqueous solution, producing $\cdot \mathrm{OH}$ radicals. This then reacted with the MB dye molecules via the oxidation reaction, degrading the products into water. ${ }^{50}$ According to the photodegradation results, the dual layered film exhibited remarkable photocatalytic removal under $\mathrm{MB}$ pollutant, leading to effective 

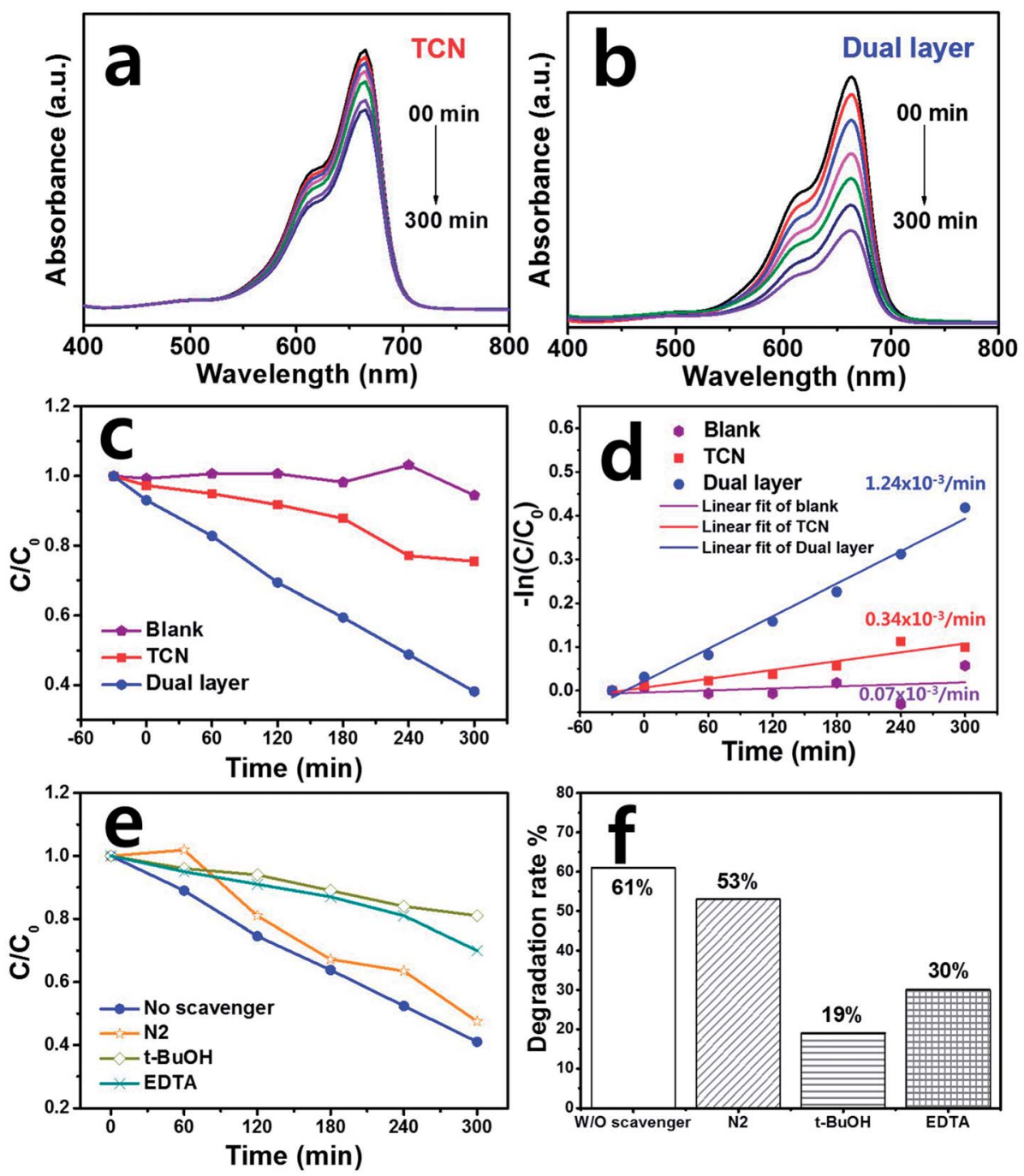

Fig. 4 Photodegradation activity of methylene blue (MB) (a) TCN film, (b) dual layered film, (c) relative absorbance of MB degradation, (d) logarithmic absorbance of MB with kinetic rate constant on pure MB solution, TCN, dual layer and (e) scavenger test, (f) degradation efficiency based on scavenger test of w/o scavenger, $\mathrm{N} 2, t-\mathrm{BuOH}$ and EDTA under visible irradiation.

separation of the photo-excited electron and hole pairs between the ternary structures and TCN interface, further promoting photo-redox reactions and the excellent removal of MB organic pollutant on the surface of the TCN film.

\section{4 $\mathrm{H}_{2}$ evolution and EIS measurements}

We investigated the hydrogen $\left(\mathrm{H}_{2}\right)$ evolution in more detail to evaluate the photoanode film itself under visible light irradiation. Fig. S3(b) $\dagger$ is the set-up for $\mathrm{H}_{2}$ evolution of the as-prepared films with a xenon-arc lamp using $a>400 \mathrm{~nm}$ cut-off filter. As shown in Fig. 5(a), the TCN and dual layered films exhibited $\mathrm{H}_{2}$ production over 5 hours. The dual layered film exhibited lower activity than the TCN film when the gas was collected during the first hour. However, significantly higher $\mathrm{H}_{2}$ activity occurred in the dual layered film than in the TCN film after 2 hours. Up to 5 hours, the dual layered film exhibited $\mathrm{H}_{2}$ production of $44.9 \mu \mathrm{mol}$, which is almost four times higher than that of the TCN film, of $11.1 \mu \mathrm{mol}$. After 5 hours of reaction time in the case of TCN film, the $\mathrm{H}_{2}$ evolution decreased slightly compared to the activity at 4 hours, suggesting both poor stability and photo-response. To assess the stability of the dual layered film, a recycling test was carried out for 10 cycles and the results are shown in Fig. 5(b). For the same experimental state, $\mathrm{N}_{2}$ gas was bubbled into the aqueous solution and then Ar was purged into the reactor after every cycle was completed. During the repeatability test, we observed almost stable $\mathrm{H}_{2}$ activities over 45 hours, except for a few cycles in which $\mathrm{H}_{2}$ production decreased. Therefore, the dual layered film exhibited superior $\mathrm{H}_{2}$ production compared to the TCN film over time. This was due to the proper interaction between the ternary structure and the TCN, enabling successful separation of charge carriers under light irradiation.

Based on these $\mathrm{H}_{2}$ production results, we used EIS measurements to measure the resistance of the photoanode film, to elucidate the relationship between the electrolyte and the heterostructures of the as-prepared film. The Nyquist plot usually exhibits charge transfer resistance with an arc radius, as shown in Fig. 5(c). The smaller semicircle of the dual layered film was observed to be $\sim 50 \mathrm{ohm} \mathrm{cm}^{2}$, while the larger plot of the TCN 

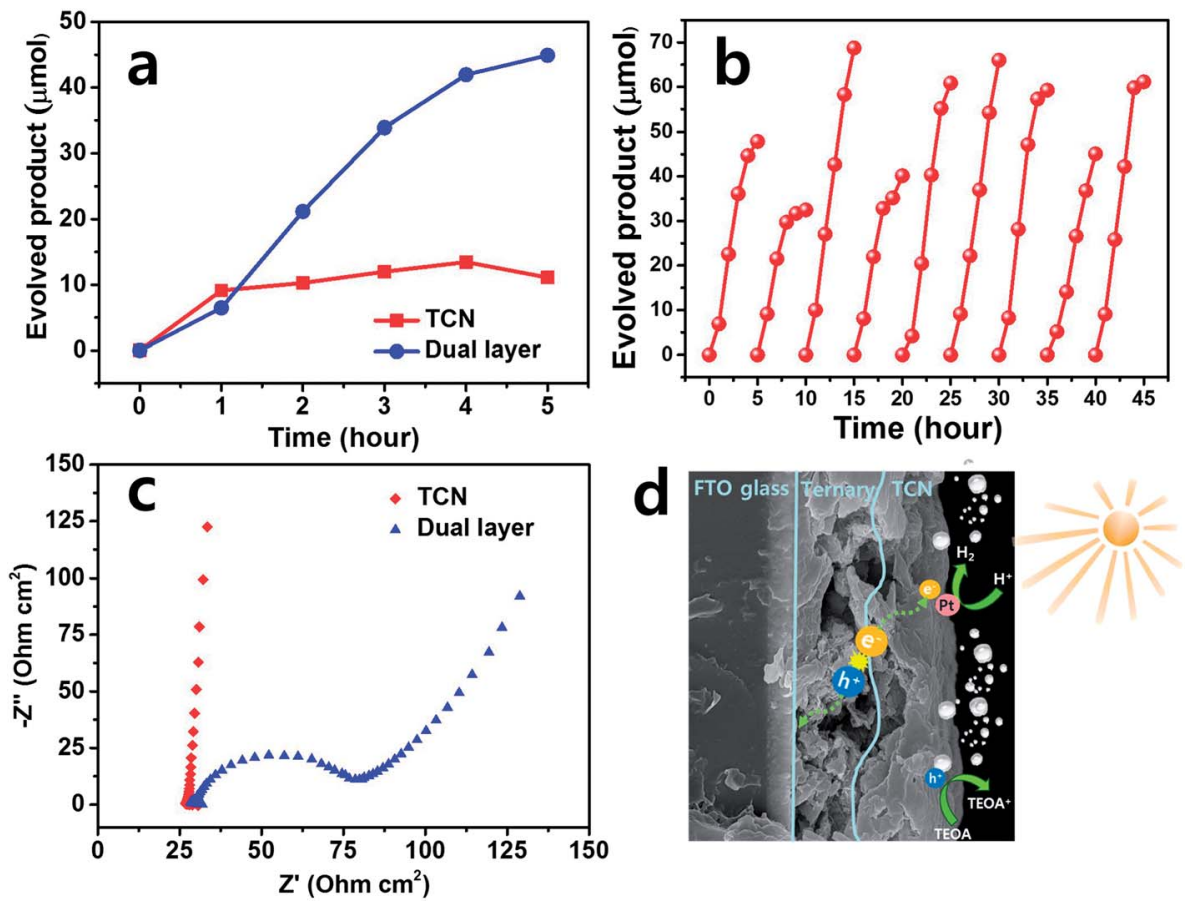

Fig. 5 (a) Hydrogen $\left(\mathrm{H}_{2}\right.$ ) evolution on TCN film and dual layered film, (b) $\mathrm{H}_{2}$ evolution recycle tests on dual layered film, (c) electrochemical impedance spectroscopy (EIS) measurement on TCN film and dual layered film and (d) its possible mechanism.

film was observed to be $\sim 2500 \mathrm{ohm} \mathrm{cm}^{2}$ under visible light irradiation, as shown in Fig. S2. $\dagger$ Thus, these EIS results confirm that the dual layered film successfully formed heterojunctions with ternary structures/TCN, as expected, reducing the interface resistance between these heterostructures and electrolyte.

Consequently, a possible mechanism can be inferred from the $\mathrm{H}_{2}$ evolution, EIS measurements as shown in Fig. 5(d). When the dual layered film was illuminated by visible light, the electronhole pairs were generated on the surface of the ternary film. Initially, the electrons $\left(\mathrm{e}^{-}\right)$were photogenerated from TCN film. Afterwards, these electrons were shifted to the Pt on the surface of the TCN film, producing $\mathrm{H}_{2}$ gas. Meanwhile, the photoinduced holes $\left(\mathrm{h}^{+}\right)$from TCN film were transferred to the ternary structures and then FTO substrate. The remaining holes in the valence band of the TCN film were captured by the TEOA, promoting $\mathrm{H}_{2}$ evolution. ${ }^{51,52}$ The interface between ternary structures and TCN acted as channels to connect as heterojunctions as well as transportation of electron and hole pairs, which both prohibits the recombination of photo-induced charge carriers and promotes excellent photocatalytic activities. Therefore, the dual layered film effectively separated the electron-hole pairs at the heterojunction interface, developing stable $\mathrm{H}_{2}$ evolution activity compared to bare TCN film.

\section{Conclusion}

We designed two different composites of ternary structures, $\mathrm{HGCNF} / \mathrm{MoS}_{2} / \mathrm{SNG}$ and bulk $\mathrm{g}-\mathrm{C}_{3} \mathrm{~N}_{4}$ from a thiourea precursor (TCN) prepared as a dual layered film using a spin coating method, for photo-responsible applications. The formation of TCN-based dual layered films on the ternary structures was well- characterized, and we identified the morphological structures and individual chemical bonds. These simplified dual layered structures revealed increasing absorption in the visible region, with a decreased band gap energy compared to bare TCN film. Moreover, the dual layered film reduced recombination rates and produced a high photoresponse due to the effective charge carrier separation, as demonstrated by our PL and transient photocurrent analysis. Based on the characterization of the asprepared films, the dual layered film exhibited exceptional photodegradation kinetic activity of $1.24 \times 10^{-3} \mathrm{~min}^{-1}$ and $\mathrm{H}_{2}$ evolution of $44.9 \mu \mathrm{mol}$ over 5 hours, with steady stability under visible light irradiation for 45 hours. Furthermore, a low impedance value of $\sim 50 \mathrm{ohm} \mathrm{cm}^{2}$ was observed in the dual layered film, suggesting that the interface between ternary structures and bulk g- $\mathrm{C}_{3} \mathrm{~N}_{4}$ reduced its resistance based on the EIS measurement. Therefore, compared to bare TCN film under visible light, our photodegradation and $\mathrm{H}_{2}$ evolution results indicate that the dual layered film composed of ternary structures and TCN improved the photo-response capabilities by facilitating the effective separation of the photo-induced electron-hole pairs.

\section{Conflicts of interest}

There is no conflict to declare.

\section{Acknowledgements}

This work was supported by a National Research Foundation of Korea (NRF) grant funded by the Korean government (Ministry of Education) (No. NRF-2016R1D1A1A02936936) and a NRF grant funded by the Korean government (MEST) (No. NRF- 
2018R1A2A1A13078704), and the Human Resources Development program (No. 20174030201830) of a Korea Institute of Energy Technology Evaluation and Planning (KETEP) grant funded by the Korea government Ministry of Trade, Industry and Energy.

\section{References}

1 M. R. Hoffmann, S. T. Martin, W. Choi and D. W. Bahnemann, Chem. Rev., 1995, 95, 69-96.

2 O. Legrini, E. Oliveros and A. M. Braun, Chem. Rev., 1993, 93, 671-698.

3 M. G. Lee, J. S. Park and H. W. Jang, J. Korean Ceram. Soc., 2018, 55, 185-202.

4 A. Fujishima and K. Honda, Nature, 1972, 238, 37.

5 A. Fujishima, T. N. Rao and D. A. Tryk, J. Photochem. Photobiol. C Photochem. Rev., 2000, 1, 1-21.

6 A. L. Linsebigler, G. Lu and J. T. Yates, Chem. Rev., 1995, 95, 735-758.

7 W. Cui, J. He, H. Wang, J. Hu, L. Liu and Y. Liang, Appl. Catal. B Environ., 2018, 232, 232-245.

8 Y. Zhang, W. Cui, W. An, L. Liu, Y. Liang and Y. Zhu, Appl. Catal. B Environ., 2018, 221, 36-46.

9 H. Wang, Y. Liang, L. Liu, J. Hu and W. Cui, J. Hazard. Mater., 2018, 344, 369-380.

10 Q. Xiang, J. Yu and M. Jaroniec, J. Am. Chem. Soc., 2012, 134, 6575-6578.

11 J. B. Priebe, J. Radnik, A. J. J. Lennox, M.-M. Pohl, M. Karnahl, D. Hollmann, K. Grabow, U. Bentrup, H. Junge, M. Beller and A. Brückner, ACS Catal., 2015, 5, 2137-2148.

12 H.-L. Liu and T. C. K. Yang, Process Biochem., 2003, 39, 475481.

13 C. Wang, B.-Q. Xu, X. Wang and J. Zhao, J. Solid State Chem., 2005, 178, 3500-3506.

14 J. Wen, J. Xie, X. Chen and X. Li, Appl. Surf. Sci., 2017, 391, 72-123.

15 L. Yang, W. Zhou, D. Hou, K. Zhou, G. Li, Z. Tang, L. Li and S. Chen, Nanoscale, 2015, 7, 5203-5208.

16 C. Zhang, Z. Wang, S. Bhoyate, T. Morey, L. B. Neria, V. Vasiraju, G. Gupta, S. Palchoudhury, K. P. Kahol, R. S. Mishra, F. Perez and K. R. Gupta, C, 2017, 3, 33.

17 C. Mu, Y. Zhang, W. Cui, Y. Liang and Y. Zhu, Appl. Catal. B Environ., 2017, 212, 41-49.

18 X. Wang, Y. Liang, W. An, J. Hu, Y. Zhu and W. Cui, Appl. Catal. B Environ., 2017, 219, 53-62.

19 H. Wang, Y. Liang, L. Liu, J. Hu, P. Wu and W. Cui, Appl. Catal. B Environ., 2017, 208, 22-34.

20 A. K. Geim and K. S. Novoselov, Nat. Mater., 2007, 6, 183.

21 M. E. M. Buan, N. Muthuswamy, J. C. Walmsley, D. Chen and M. Rønning, ChemCatChem, 2017, 9, 1663-1674.

22 T. F. Jaramillo, K. P. Jørgensen, J. Bonde, J. H. Nielsen, S. Horch and I. Chorkendorff, Science, 2007, 317, 100.

23 M. Kotal, J. Kim, K. J. Kim and I.-K. Oh, Adv. Mater., 2016, 28, 1610-1615.

24 F. He, G. Chen, Y. Yu, S. Hao, Y. Zhou and Y. Zheng, ACS Appl. Mater. Interfaces, 2014, 6, 7171-7179.
25 Y. Sun and K. Yan, J. Adv. Oxid. Technol., 2016, 19, 376.

26 N. Nalajala, K. K. Patra, P. A. Bharad and C. S. Gopinath, RSC Adv., 2019, 9, 6094-6100.

27 S. Kang, J. Jang, S.-h. Ahn and C. S. Lee, Dalton Trans., 2019, 48, 2170-2178.

28 L. Yang, X. Cui, J. Zhang, K. Wang, M. Shen, S. Zeng, S. A. Dayeh, L. Feng and B. Xiang, Sci. Rep., 2014, 4, 5649.

29 W. Fu, H. He, Z. Zhang, C. Wu, X. Wang, H. Wang, Q. Zeng, L. Sun, X. Wang, J. Zhou, Q. Fu, P. Yu, Z. Shen, C. Jin, B. I. Yakobson and Z. Liu, Nano Energy, 2016, 27, 44-50.

30 A. Enesca, L. Isac and A. Duta, Appl. Catal. B Environ., 2015, 162, 352-363.

31 Y. Byun, M. Cho, D. Kim, Y. Jung and A. Coskun, Macromolecules, 2017, 50, 523-533.

32 J. Yuan, G. Chen, W. Weng and Y. Xu, J. Mater. Chem., 2012, 22, 7929-7936.

33 B. Zhu, P. Xia, W. Ho and J. Yu, Appl. Surf. Sci., 2015, 344, 188-195.

34 F. Dong, Y. Li, Z. Wang and W.-K. Ho, Appl. Surf. Sci., 2015, 358, 393-403.

35 L. Ma, H. Fan, K. Fu, S. Lei, Q. Hu, H. Huang and G. He, ACS Sustainable Chem. Eng., 2017, 5, 7093-7103.

36 J. Li, B. Shen, Z. Hong, B. Lin, B. Gao and Y. Chen, Chem. Commun., 2012, 48, 12017-12019.

37 P.-K. Chuang, K.-H. Wu, T.-F. Yeh and H. Teng, ACS Sustainable Chem. Eng., 2016, 4, 5989-5997.

38 L. Ye, D. Wang and S. Chen, ACS Appl. Mater. Interfaces, 2016, 8, 5280-5289.

39 M.-h. Wu, L. Li, Y.-c. Xue, G. Xu, L. Tang, N. Liu and W.-y. Huang, Appl. Catal. B Environ., 2018, 228, 103-112.

40 S. J. Kerber, T. L. Barr, G. P. Mann, W. A. Brantley, E. Papazoglou and J. C. Mitchell, J. Mater. Eng. Perform., 1998, 7, 329-333.

41 M. N. Islam, T. B. Ghosh, K. L. Chopra and H. N. Acharya, Thin Solid Films, 1996, 280, 20-25.

42 H. Li, F. Xie, W. Li, B. D. Fahlman, M. Chen and W. Li, RSC Adv., 2016, 6, 105222-105230.

43 J. E. Lee, J. Jung, T. Y. Ko, S. Kim, S.-I. Kim, J. Nah, S. Ryu, K. T. Nam and M. H. Lee, RSC Adv., 2017, 7, 5480-5487.

44 X. Zheng, J. Xu, K. Yan, H. Wang, Z. Wang and S. Yang, Chem. Mater., 2014, 26, 2344-2353.

45 L. Hu, X. Liu, S. Dalgleish, M. M. Matsushita, H. Yoshikawa and K. Awaga, J. Mater. Chem. C, 2015, 3, 5122-5135.

46 L.-R. Zou, G.-F. Huang, D.-F. Li, J.-H. Liu, A.-L. Pan and W.-Q. Huang, RSC Adv., 2016, 6, 86688-86694.

47 H. Li, Y. Jing, X. Ma, T. Liu, L. Yang, B. Liu, S. Yin, Y. Wei and Y. Wang, RSC Adv., 2017, 7, 8688-8693.

48 A. Ali and W.-C. Oh, J. Korean Ceram. Soc., 2017, 54, 205-210. 49 F. Wu, X. Li, W. Liu and S. Zhang, Appl. Surf. Sci., 2017, 405, 60-70.

50 T. J. Park, R. C. Pawar, S. Kang and C. S. Lee, RSC Adv., 2016, 6, 89944-89952.

51 R. R. Prabhakar, W. Septina, S. Siol, T. Moehl, R. Wick-Joliat and S. D. Tilley, J. Mater. Chem. A, 2017, 5, 23139-23145.

52 E. Pastor, F. Le Formal, M. T. Mayer, S. D. Tilley, L. Francàs, C. A. Mesa, M. Grätzel and J. R. Durrant, Nat. Commun., 2017, 8, 14280 . 